\title{
Time-Resolved Freely Dissolved Concentrations of Semivolatile and Hydrophobic Test Chemicals in In Vitro Assays - Measuring High Losses and Crossover by Headspace Solid-Phase Microextraction
}

Birch, Heidi; Kramer, Nynke I.; Mayer, Philipp

Published in:

Chemical Research in Toxicology

Link to article, DOI:

10.1021/acs.chemrestox.9b00133

Publication date:

2019

Document Version

Peer reviewed version

Link back to DTU Orbit

Citation (APA):

Birch, H., Kramer, N. I., \& Mayer, P. (2019). Time-Resolved Freely Dissolved Concentrations of Semivolatile and Hydrophobic Test Chemicals in In Vitro Assays - Measuring High Losses and Crossover by Headspace SolidPhase Microextraction. Chemical Research in Toxicology, 32(9), 1780-1790.

https://doi.org/10.1021/acs.chemrestox.9b00133

\section{General rights}

Copyright and moral rights for the publications made accessible in the public portal are retained by the authors and/or other copyright owners and it is a condition of accessing publications that users recognise and abide by the legal requirements associated with these rights.

- Users may download and print one copy of any publication from the public portal for the purpose of private study or research.

- You may not further distribute the material or use it for any profit-making activity or commercial gain

- You may freely distribute the URL identifying the publication in the public portal 


\section{Article}

\section{Time-Resolved Freely Dissolved Concentrations of Semi-Volatile and Hydrophobic Test Chemicals in In Vitro Assays - Measuring High Losses and Crossover by Headspace Solid-Phase Microextraction}

Heidi Birch, Nynke Irene Kramer, and Philipp Mayer

Chem. Res. Toxicol., Just Accepted Manuscript • DOI: 10.1021/acs.chemrestox.9b00133 • Publication Date (Web): 20 Aug 2019

Downloaded from pubs.acs.org on August 26, 2019

\section{Just Accepted}

"Just Accepted" manuscripts have been peer-reviewed and accepted for publication. They are posted online prior to technical editing, formatting for publication and author proofing. The American Chemical Society provides "Just Accepted" as a service to the research community to expedite the dissemination of scientific material as soon as possible after acceptance. "Just Accepted" manuscripts appear in full in PDF format accompanied by an HTML abstract. "Just Accepted" manuscripts have been fully peer reviewed, but should not be considered the official version of record. They are citable by the Digital Object Identifier (DOI尺). "Just Accepted" is an optional service offered to authors. Therefore, the "Just Accepted" Web site may not include all articles that will be published in the journal. After a manuscript is technically edited and formatted, it will be removed from the "Just Accepted" Web site and published as an ASAP article. Note that technical editing may introduce minor changes to the manuscript text and/or graphics which could affect content, and all legal disclaimers and ethical guidelines that apply to the journal pertain. ACS cannot be held responsible for errors or consequences arising from the use of information contained in these "Just Accepted" manuscripts. 


\title{
Time-Resolved Freely Dissolved Concentrations of Semi- Volatile and Hydrophobic Test Chemicals in In Vitro
}

\section{Assays - Measuring High Losses and Crossover by Headspace Solid-Phase Microextraction}

\author{
Heidi Birch ${ }^{\dagger}$, Nynke I. Kramert, Philipp Mayer ${ }^{\dagger}$ \\ 'Department of Environmental Engineering, Technical University of Denmark, Bygningstorvet, \\ Building 115, 2800 Kgs. Lyngby, Denmark.
}

Institute for Risk Assessment Sciences, Utrecht University, Utrecht, The Netherlands.

Keywords: In vitro exposure, Sorption, Microtiter plates, Air-water partitioning, Binding to medium constituents 


\section{TOC graphic}

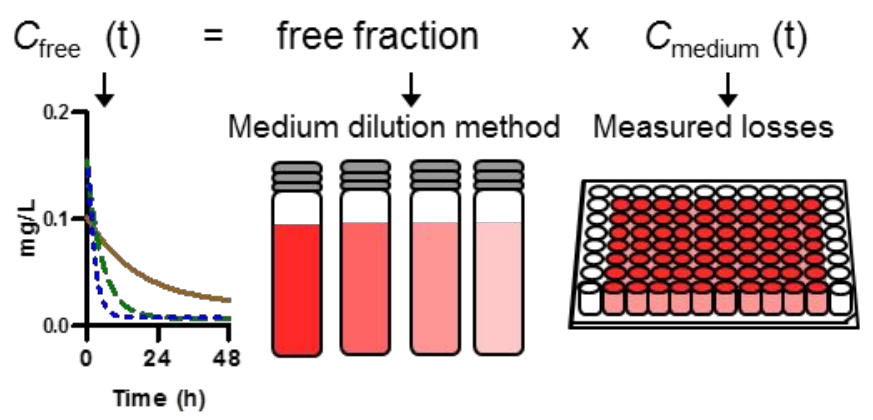

16

17

18

19

20

21

22

23

24

25

26

27

28

29

30

31

32

33

34

35

36

37

38

39

40

41

42

43

44

45

46

47

48

49

50

51

52

53

54

55

56

57

58

59

60

ACS Paragon Plus Environment 


\section{Abstract}

In vitro assays are normally conducted in plastic multi-well plates open to exchange with the ambient air. The concentration of test substances freely available to cells is often not known, can change over time, and is difficult to measure in the small volumes in microplates. However, even a well-characterized toxicological response is of limited value if it cannot be linked to a welldefined exposure level. The aim of this study was to develop and apply an approach for determining time resolved freely dissolved concentrations of semi-volatile and hydrophobic organic chemicals (SVHOCs) in in vitro assays: (1) free fractions were measured by a new medium dilution method and (2) time-resolved loss curves were obtained by measurements of total concentrations in 96-well plates during incubations at $37^{\circ} \mathrm{C}$. Headspace solid-phase microextraction was used as an analytical technique for 24 model chemicals spanning 6 chemical groups and 4-5 orders of magnitude in $K_{\mathrm{ow}}$ and $K_{\mathrm{aw}}$. Free fractions were above $30 \%$ for chemicals with $\log K_{\mathrm{ow}}<3.5$ and then decreased with increasing $\log K_{\mathrm{ow}}$. Medium concentrations declined significantly $(>50 \%)$ within 24 hours of incubation for all 20 chemicals having $\log K_{\mathrm{ow}}>4$ or $\log K_{\mathrm{aw}}>-3.5$ in serum free medium. Losses of chemicals were lower for medium containing $10 \%$ fetal bovine serum, most significantly for chemicals with $\log K_{\mathrm{ow}}>4$. High crossover to neighboring wells was observed also below $\log K_{\text {ow }}$ of 4 and $\log K_{\text {aw }}$ of -3.5 . Sealing the well plates had limited effect on the losses, but clearly reduced crossover. The high losses and crossover of most tested chemicals question the suitability of multi-well plates for in vitro testing of SVHOCs, and call for (1) test systems that minimize losses, (2) methods to control in vitro exposure, (3) analytical confirmation of exposure and (4) exposure control and confirmation being included in good in vitro reporting standards. 


\section{Introduction}

In vitro toxicity tests are increasingly used to determine the toxicological profile of chemicals. The test results are normally based on the nominal concentration of a test chemical added to the culture medium at the start of the test. However, several studies have found that volatile and/or hydrophobic chemicals evaporate from wells, ${ }^{1-4}$ cross over to adjacent wells,,${ }^{5}$ sorb to microtiter plates, ${ }^{1,2,6,7}$ and sorb to medium constituents. ${ }^{1,2,6,8}$ Therefore, the actual exposure of the cells to the test substances is often not known and decreases with time, which can lead to reduced toxicity and assay sensitivity. ${ }^{1,2,9,10}$ Changes in assay setup affect the losses and thereby alter the toxicity parameter based on nominal concentrations. ${ }^{11}$ This hampers comparisons of effect data generated using different in vitro bioassay setups and between different chemicals. ${ }^{2,8}$ These exposure issues can limit the applicability, value and relevance of in vitro toxicological data since even a well-characterized toxicological response is of limited value if it cannot be linked to a well-defined exposure level.

Within environmental in vitro toxicity testing with fish cells or embryos, exposure verification is more common, ${ }^{12,13}$ and required in newer guidelines. ${ }^{14,15}$ Within in vitro testing with human and mammalian cells, recommendations regarding the proper dose metric for evaluating the results have been put forward: ${ }^{2}$ if $>20 \%$ of the test chemical is bound to medium constituents or the test chemical has a $\log K_{\mathrm{ow}}>2$, internal concentration measurements should if possible be used as dose metric (e.g. as determined by extraction of the cells). If internal concentration measurements are not possible, freely dissolved concentrations, $C_{\text {free }}$ (dissolved in the test medium and not bound to particulate or dissolved organic matter such as lipids and proteins), should be used as dose metric. ${ }^{2}$ 
Three approaches can then be taken for making exposure better defined in in vitro tests: 1) to design in vitro test systems where concentrations are kept constant during the test, 2) to measure exposure during the test or 3) to model exposure during the tests based on physicochemical properties of the test substances.

In high-throughput toxicity screening tests, the optimal scenario is to design in vitro test systems where the exposure is constant and controlled during the test. ${ }^{16}$ Passive dosing is a promising approach for this.$^{17}$ It has mainly been used in larger volumes such as microplates with 24 wells and vials. ${ }^{9} 16,18-20$ However, designing passive dosing systems for in vitro tests is not straightforward since the tests require specific conditions relating to growth surface, growth medium, $\mathrm{CO}_{2}$ level, and since contact between the cells and the passive dosing phase should be avoided (direct contact will make it hard to determine the exposure level). No such design has yet been demonstrated for well plates with 96, 384 or 1536 wells.

The second possibility is to measure the exposure during or at the end of in vitro tests. Solid phase microextraction (SPME) is currently the most promising method for determining $C_{\text {free }}$ of hydrophobic chemicals. ${ }^{16}$ It has successfully been used in microplates with 24 wells to determine $C_{\text {free }}$ of phenanthrene using the negligible depletion SPME regime. ${ }^{1}$ However, in the small volumes of wells in microplates with 96 or more wells, it is generally not possible to fulfil the negligible depletion requirement, and the $C_{\text {free }}$ can then not be measured directly in the wells.

The third possibility is to model the exposure based on physicochemical properties of the test chemicals. Mass balance models have been developed for determining the distribution of organic chemicals in closed test systems, ${ }^{21}$ to take lipid and protein binding within the serum into account when estimating $\mathrm{EC}_{50}$-values, ${ }^{22}$ and to include system specific loss processes such as 
binding to well plate plastic and cell partitioning. ${ }^{1,6}$ The models rely generally on a complete mass balance assumption (i.e. no losses out of the wells), ${ }^{1}$ and are thus not suited to account for and predict evaporative losses and cross-over.

This work advances the methods to measure exposure during in vitro tests i.e. the second possibility. The aim was to develop and apply a methodology for the analytical determination of the available exposure of hydrophobic chemicals in in vitro assays using microplates with 96 wells. The approach is based on three steps:

1) Test medium is spiked with test chemicals at nominal concentrations, $C_{\text {nominal. }}$.

2) The free fraction of test chemicals in the medium, $f f$ (i.e. unbound fraction), is measured in 20 $\mathrm{mL}$ vials using headspace solid-phase microextraction (HS-SPME). ${ }^{1,23}$ The SPME fiber is positioned in the headspace above the medium sample in order to avoid medium constituents and bound chemicals on the fiber surface.

3) Loss of test chemicals from the medium is determined for 96 well plates during incubation at $37^{\circ} \mathrm{C}$. Samples from the wells are transferred to $20 \mathrm{~mL}$ vials for measurements of total test chemical concentrations with HS-SPME coupled to GC/MS. For such measurements of total concentration, negligible depletion of the test chemical is not required. Samples are taken at different time points to determine the total concentrations in the test medium $C_{\text {medium }}(\mathrm{t})$ relative to the total concentrations in spiked but not incubated medium, $C_{\text {medium }}(\mathrm{t}=0)$. During these measurements the $C_{\text {medium }}(\mathrm{t}) / C_{\text {medium }}(\mathrm{t}=0)$ can be evaluated directly by the MS signal without converting to the actual concentrations when being in the linear range of the GC/MS detector. 
The freely dissolved concentration, $C_{\text {free }}\left[\right.$ freely dissolved mass $\times$ volume medium $\left.{ }^{-1}\right]$, is then calculated by equation 1 .

$C_{\text {free }}(t)=C_{\text {nominal }} \cdot f f \cdot \frac{C_{\text {medium }}(t)}{C_{\text {medium }}(t=0)}$

Here we assume the kinetics of binding to medium constituents to be much faster than the evaporative losses and sorption to well plate plastic during the incubation of the in vitro tests.

Semi-volatile and hydrophobic chemicals is a large and diverse group of chemicals that include many priority pollutants such as PAHs, PCBs, phthalates, petroleum hydrocarbons, organochlorine pesticides and many fragrances. 24 chemicals were chosen for this study from a number of chemical groups: polycyclic aromatic hydrocarbons, biphenyls, chlorobenzenes, brominated structures, neutral pesticides, and other neutral chemicals. The chemicals were chosen to cover the chemical space of octanol-water partition ratios, $\log K_{\mathrm{ow}}$, between 2 and 6 , and of air-water partition ratios at $37^{\circ} \mathrm{C}, K_{\mathrm{aw}}$, between $10^{-5}$ and 0.2 . The chemicals covered a boiling point range from 132 to $437^{\circ} \mathrm{C}$. The $C_{\text {free }}$ and losses from test systems were determined in three different test media used commonly in in vitro assays. Fetal bovine serum is rich in lipids and proteins, and the most common supplement for cell culture media. ${ }^{24}$ The first test medium had a high concentration of serum ( $10 \%$ fetal bovine serum), which is used e.g. for AREc32 and AhR rat assays. The second test medium had a lower concentration of serum ( $2 \%$ charcoalstripped fetal bovine serum), which is used e.g. for the GeneBLAzer assays. The third medium was serum free and contained N2-supplement (1\%), which is used as a differentiation medium when culturing neurospheres..$^{25,26}$ Thus, the study covered a large span in binding capacities of the medium. 


\section{Experimental procedures}

Theoretical considerations for determining free fractions. We developed and applied a new medium dilution method for determining free fractions of the test chemicals. The method is a modification of the sediment dilution method developed by Ter Laak et $\mathrm{al}^{27}$, where sediment is spiked and diluted producing a series of sediment-water suspensions. Measurements of freely dissolved concentrations are then used to deduce sediment-water partition ratios. ${ }^{27}$ This method does however not apply directly to in vitro media because the mass of sorbents in the media is small (typically below 1\%) and most often not known, and because the media contains water before dilution. The objective of the new medium dilution method was therefore to measure free fractions of chemicals in the spiked medium and not directed at obtaining partition ratios (where the amount of sorbents would be needed). In the following it is therefore assumed that the volume of sorbents in the medium is negligible compared to the volume of water in the medium so that the freely dissolved concentration in the medium, $C_{\text {free, }}$ can be approximated by the freely dissolved mass of the chemical divided by the volume of the medium.

When medium is spiked at a nominal concentration of $C_{\text {medium, }}$, the free fraction at equilibrium is defined as (equation 2):

$f f=\frac{C_{\text {free }}}{C_{\text {medium }}}=\frac{C_{\text {free }}}{C_{\text {bound }}+C_{\text {free }}}(2)$

where $C_{\text {free }}$ is the freely dissolved concentration in the medium [freely dissolved mass of the chemical $\times$ volume medium ${ }^{-1}$ ] and $C_{\text {medium }}$ is the total concentration in the medium [total mass of the chemical in the medium $\times$ volume medium $\left.{ }^{-1}\right] . C_{\text {bound }}$ is the bound concentration in the medium [mass of the chemical bound to medium constituents $\times$ volume medium ${ }^{-1}$ ], and can be further described by equation (3), 
$C_{\text {bound }}=C_{\text {bound,const }} \cdot C_{\text {const,medium }}(3)$

where $C_{\text {bound,const }}$ is the bound concentrations in the constituents [mass of the chemical bound to medium constituents $\times$ mass of medium constituents ${ }^{-1}$ ], and $C_{\text {const,medium }}$ is the concentration of constituents in the medium [mass of medium constituent $\times$ volume medium ${ }^{-1}$ ].

The spiked medium is diluted with pure water, and we define the dilution factor, $D F$, as (equation 4):

$D F=\frac{V_{\text {water }}}{V_{\text {medium }}}(4)$ where $V_{\text {water }}$ is the volume of water used for diluting the volume of spiked medium, $V_{\text {medium }}$, to reach a total diluted volume $V_{\text {diluted }}$. This dilution can be described by the following three equations (5-7):

$V_{\text {diluted }}=V_{\text {water }}+V_{\text {medium }}(5)$

$C_{\text {bound,diluted }}=C_{\text {bound,const,diluted }} \cdot C_{\text {const,diluted }}(6)$

$C_{\text {const, diluted }} \cdot V_{\text {diluted }}=C_{\text {const,medium }} \cdot V_{\text {medium }}(7)$

where $C_{\text {bound,diluted }}$ is the bound concentration in the diluted medium [mass bound to medium constituents after dilution $\times$ volume diluted medium $\left.{ }^{-1}\right], C_{\text {bound,const,diluted }}$ is the bound concentration in the constituents after dilution [mass bound to medium constituents after dilution $\times$ mass of medium constituents ${ }^{-1}$ ] and $C_{\text {const,diluted }}$ is the concentration of constituents in the diluted medium [mass of medium constituent $\times$ volume diluted medium $\left.{ }^{-1}\right]$.

Assuming linear medium-water partition isotherms, $K_{\mathrm{D}}$, within the applied dilution range (applicable for hydrophobic chemicals at low concentrations) and at low sorbent concentrations, leads to equation (8):

$K_{D}=\frac{C_{\text {bound,const }}}{C_{\text {free }}}=\frac{C_{\text {bound, } \text {,onst }, \text { diluted }}}{C_{\text {free, } \text { ilituted }}}(8)$ 
where $C_{\text {free,diluted }}$ is the freely dissolved concentration in diluted medium [freely dissolved mass $\times$ volume of diluted medium $\left.{ }^{-1}\right]$.

If the water:air volume ratio in the test vial is kept above $3: 1$, then the depletion of the chemical by partitioning to the headspace will be less than $5 \%$ of the total chemical in the vial for chemicals with $K_{\mathrm{aw}}<0.15$, and can therefore be neglected. All chemicals used here have airwater partitioning below this limit. At equilibrium, the dilution series can be described by a mass balance stating that the chemical mass before dilution equals the mass after dilution, distributed between the free and bound forms (equation 9):

$C_{\text {medium }} \cdot V_{\text {medium }}=C_{\text {free, diluted }} \cdot V_{\text {diluted }}+C_{\text {bound,diluted }} \cdot V_{\text {diluted }}$

Combining equation 2-9 (Supporting Information S2) leads to the relationship between the freely dissolved concentration in the diluted medium, $C_{\text {free,diluted }}$ and the freely dissolved concentration in the medium before dilution, $C_{\text {free }}$ (equation 10$)$ :

$\frac{C_{\text {free, diluted }}}{C_{\text {free }}}=1-\frac{D F}{D F+f f^{-1}}$

Measuring the ratio of $C_{\text {free,diluted }} / C_{\text {free }}$ using SPME in a dilution series of the spiked medium will therefore reveal the $f f$ based on a plot of $C_{\text {free,diluted }} / C_{\text {free }}$ against the $D F$, and the $f f$ can be found as $1 / D F$ when $C_{\text {free,diluted }} / C_{\text {free }}=0.5$. The free fractions can then be used to determine the enhanced capacity $(E)$ of the medium relative to pure water $(E=1 / f f),{ }^{28,29}$ which numerically equals the medium to water partition coefficient. ${ }^{6}$

Materials. Benzo[h]quinolone, biphenyl, chlorobenzene, chlorocresol, chlorpropham, 1,2dibromo-3-chloropropane, 4,4'-dichlorobiphenyl (PCB15), dicofol, diethyl phthalate, hexachlorobenzene, hexachlorocyclohexane (lindane), $\beta$-ionone, 9-methylanthracene, naphthalene, nitrapyrin, 2,2',5,5'-pentachlorobiphenyl (PCB52), pentachlorobenzene, 
phenanthrene, tetralin, 1,3,5-trichlorobenzene and 1,3,5-tribromobenzene were purchased from Sigma Aldrich (Copenhagen, Denmark). Benz(a)anthracene, fluoranthene and $n$-nitrosodi- $n$ butylamine was purchased from TCI chemicals (Zwijndrecht, Belgium). The purity of all chemicals mentioned above was at least 96\%. Opti-MEM ${ }^{\mathrm{TM}}$ I Reduced Serum Medium, no phenol red (Opti-MEM); Dulbecco's Modified Eagle Medium, high glucose, GlutaMAX ${ }^{\mathrm{TM}}$ Supplement, pyruvate (DMEM); Fetal Bovine Serum, charcoal stripped, USDA-approved regions (cs-FBS); Fetal Bovine Serum, qualified, Australia origin (FBS); N2-Supplement and Ham's F-12 Nutrient Mix, GlutaMAX Supplement were purchased from Thermo Fisher Scientific (Roskilde, Denmark). Methanol (Sigma-Aldrich, purity $>99.9 \%$ ) was used for spiking and $\mathrm{NaCl}$ (Sigma-Aldrich, purity $>99.5 \%$ ) was used for preparation of saline water. Corning ${ }^{\circledR}$ 96 Well Clear Polystyrene Microplate, clear flat bottom, matrix active group TC-treated, sterile, with lid, and Corning ${ }^{\circledR}$ microplate sealing tape, aluminum, non-sterile, were purchased from Sigma Aldrich (Copenhagen, Denmark) and used for loss experiments.

Preparation of spiked media. Vials and glassware were heated at $80^{\circ} \mathrm{C}$ for 2 hours prior to the experiments and then cooled to room temperature. The 24 chemicals were mixed in methanol to prepare a spiking mixture of $200-2000 \mathrm{mg} / \mathrm{L}$. The spiking mixture was stored at $-18^{\circ} \mathrm{C}$ between experiments. A new spiking mixture with slightly different concentrations was prepared during the study and used for the loss experiment using 10\% FBS medium. Three types of media were prepared 1) $10 \%$ Fetal Bovine Serum (FBS) in 90\% DMEM GlutaMAX (hereafter referred to as 10\% FBS medium), 2) 2\% charcoal-stripped Fetal Bovine Serum (cs-FBS) in 98\% Opti-MEM (hereafter referred to as 2\% cs-FBS medium), 3) 1\% N2-supplement in $33 \%$ Hams F12 GlutaMAX and 65\% DMEM GlutaMAX (hereafter referred to as 1\% N2-supplement medium), in either $100 \mathrm{~mL}$ (free fraction experiments) or $50 \mathrm{~mL}$ volumetric flasks (loss experiments). The 
media were spiked with $0.5 \%$ spiking mixture (free fraction experiments) or $0.33 \%$ spiking mixture (loss experiments) and shaken at 1200-1500 rpm for 15 minutes for equilibration.

Determination of free fraction. Each spiked medium was diluted to prepare triplicate dilution series using dilution factors of $1,4,9,50,100,500$ and 1000 . Slightly saline water $(6.4 \mathrm{~g} \mathrm{NaCl} / \mathrm{L}$ in pure water) was used for dilutions to conserve the ion strength of the dilutions. Varying volumes of the slightly saline water was added to $20 \mathrm{~mL}$ headspace vials and $15,7.5,3,1.5,0.3$, $0.15,0.03$ and $0.015 \mathrm{~mL}$ of the spiked medium was added to reach a total of $15 \mathrm{~mL}$ in the vials. The ratio between the $C_{\text {free }}$ in the spiked medium and the spiked diluted medium was then determined by automated equilibration of the SPME fiber with the dilutions through the headspace at $37^{\circ} \mathrm{C}$ without further sample preparation.

Losses during incubation. Chemicals and medium were added to six 96-well plates according to the illustration in Figure 1. DMEM or Opti-MEM without serum was added to an outer ring of wells (grey on Figure 1). Non-spiked medium was added to 12 wells (blue wells marked with 4 and 5 in Figure 1) for determination of crossover to neighboring wells. $200 \mu \mathrm{L}$ spiked medium was added to 18 wells (red wells marked with 1,2 and 3 in Figure 1) for determination of losses from wells. Half of the well plate was covered with aluminum microplate sealing tape. The remaining spiked medium was stored in the fridge and used to prepare a reference sample for every time step. 


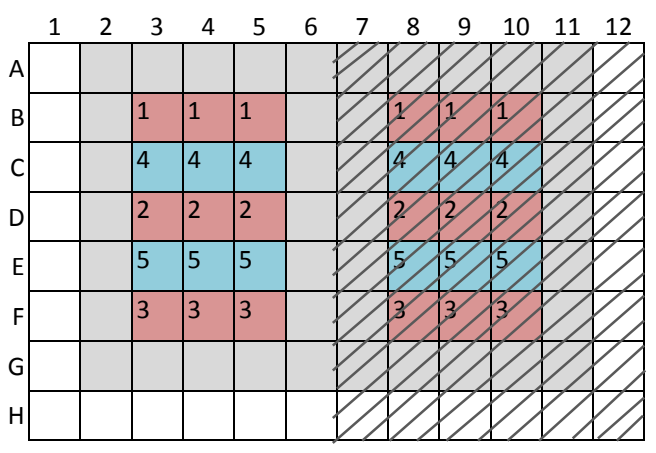

Figure 1. Spiking scheme in 96-well plates used for loss tests. Red wells marked with 1, 2 or 3 indicate spiked medium, blue wells marked with 4 or 5 indicate non-spiked medium, grey wells indicate DMEM or Opti-MEM medium without serum, striped half indicates wells closed with aluminum microplate sealing tape.

The well plates were incubated at $37^{\circ} \mathrm{C}$ for $0.5,2,6,24,48$ and 72 hours $(10 \% \mathrm{FBS}$ and $2 \%$ csFBS medium) or $0.5,2,5.5,24,72$ and 120 hours (1\% N2-supplement medium). Humidity was raised by placing $250 \mathrm{~mL}$ saline water $(18 \mathrm{~g} / \mathrm{L})$ in wide beakers in the oven during incubation and refilling with pure water at sampling points $\geq 24$ hours. After incubation, the well plates were sampled by pooling $100 \mu \mathrm{L}$ from three adjacent wells in a $20 \mathrm{~mL}$ headspace vial to form one sample (each time step thus produced three spiked and two non-spiked samples from the closed and open section of the well plate, see Figure 1). $30 \mu \mathrm{L}$ methanol was added to each sample for conservation. In the headspace vial, the transferred chemical re-distributes between its bound form, free form and the headspace, and an SPME fiber was used in the headspace to obtain a GC-MS signal proportional to the total concentration in the vial. Samples were analyzed within 20 hours of sampling.

A small test was performed in order to evaluate how much of the test chemical was lost during the well plate set-up and sampling steps (due to volatilization in the pipette during transfer, 
volatilization from the well within the first minutes of incubation, sorption to plastic pipette tip during transfer, and sorption to well plate plastic within the first minutes of incubation). This was evaluated by triplicate samples pipetted into well plates and within minutes sampled from the wells compared to triplicate reference samples taken using a gas tight glass syringe and directly added to headspace vials. $<15 \%$ losses were seen for 21 of 25 chemicals, with the highest losses observed for N-nitrosodid-n-butylamine (29\%) and Chlorpropham (22\%).

Evaporation of medium during incubation was measured gravimetrically in a closed and an open well plate containing $200 \mu \mathrm{L}$ DMEM in each well and incubated under the same conditions as the loss experiments regarding temperature and humidity. Approximately $3 \%$ of the medium evaporated from open well plates and $0.5 \%$ from closed wells plates in 24 hours ( $9 \%$ and $1.5 \%$ in total over 72 hours).

Analysis. Samples were analyzed using automated headspace SPME (PAL RSI 85 auto sampler) coupled to GC/MS (Agilent Technologies 7890B/5877A GC/MSD). For the free fraction analysis, SPME was operated in headspace mode at $37^{\circ} \mathrm{C}$ in order to obtain a GC/MS response proportional to the headspace concentration above the sample at the relevant temperature, which in turn is proportional to the freely dissolved concentration in the sample. Pre-heating of the vials was set to 10 minutes followed by 60 minutes sampling using a $7 \mu \mathrm{m}$ PDMS fiber (Supelco, Bellefonte) and an agitation of $250 \mathrm{rpm}$ alternating 5 seconds on, 2 seconds off. After sampling, the fiber was desorbed in splitless mode for 5 minutes at $315^{\circ} \mathrm{C}$ in the $\mathrm{GC}$ inlet. A post desorption conditioning of 5 minutes at $320^{\circ} \mathrm{C}$ was used. Chemicals were separated using helium as carrier gas on a $60 \mathrm{~m}$ DB- $5 \mathrm{~ms}$ column with an inner diameter of $250 \mu \mathrm{m}$ and a $0.25 \mu \mathrm{m}$ film thickness at a flow rate of $1.2 \mathrm{~mL} / \mathrm{min}$. The oven temperature started at $50^{\circ} \mathrm{C}$ with a hold of 5 minutes followed by a ramp of $15^{\circ} \mathrm{C} /$ minute to $175^{\circ} \mathrm{C}$ and a hold of 1 minute followed by a ramp 
of $10^{\circ} \mathrm{C} /$ minute to $310^{\circ} \mathrm{C}$ and a hold of 5 minutes. The MS was operated in SIM mode using at least two ions for each chemical.

The analytical basis for determining losses during incubation has recently been established for the biodegradation testing of (semi)volatile organics, where SPME was used to measure a temporal decline in the relative concentration based on peak area ratios..$^{30,31}$ Thus, for the loss analyses, SPME was operated in headspace mode at $50^{\circ} \mathrm{C}$, aiming for sensitive, precise and contactless measurements of analyte concentrations in the sample, relative to the initial concentrations. Pre-heating of the vials was set to 5 minutes followed by 30 minutes sampling. Shaking, desorption and GC/MS details were similar to the ones for free fraction analyses.

Data treatment. In order to determine the free fractions, the peak area of the quantifier ion for each chemical in the medium dilutions were divided by the peak area in the medium that was not diluted to determine the ratio $C_{\text {free,diluted }} / C_{\text {free. }}$ Thus, linearity of the MS signal was assumed within the concentration range of 1-2 orders of magnitude below the initial concentration. This ratio was then plotted as a function of $D F$ and fitted to equation 10 using GraphPad Prism 8.0.1 to obtain the $f f$ for each chemical in each medium. The log transformed $f f$ was used for the fitting and $f f$ was constrained to values $\leq 1$. Dicofol had a too low signal to get reliable results for the $f f$, and PCB52 showed $C_{\text {free,diluted }} / C_{\text {free }}$ ratios above 1.5 in media 3 . These data were therefore excluded from the $f f$ dataset. $C_{\text {free,diluted }} / C_{\text {free }}$ ratios of benz(a)anthracene were close to unity in all the prepared dilutions of medium 1 and medium 2, and $f f$ could therefore not be determined with the chosen $D F$ s for these two media. 
In order to determine the loss curves for the well plates, the peak area for each chemical measured in the medium from the spiked wells, $A_{\text {spiked, }}$, was divided by the peak area measured in the reference sample, $A_{\text {reference}}$, for each time-point (equation 11).

$$
C_{\text {medium }}=\frac{A_{\text {spiked }}}{A_{\text {reference }}} \cdot 100 \%(11)
$$

Crossover between wells was also determined relative to the reference sample (equation 12).

$C_{\text {crossover }}=\frac{A_{\text {non-spiked }}}{A_{\text {reference }}} \cdot 100 \%(12)$

Loss curves were prepared in GraphPad Prism. The reference sample at $2 \mathrm{~h}$ in the $10 \% \mathrm{FBS}$ medium showed lower peak area than the rest of the reference samples, and for this medium this time point was removed from the data set. Test substance losses from the open and closed well plates were fitted to a 'one phase decay' model in Graphpad Prism (equation 13), where the first order rate constant, $k$, and the plateau were fitted.

$C_{\text {medium }}(t)=(100 \%-$ Plateau $) \cdot e^{-k \cdot t}+$ Plateau $(13)$

Without determining the exact kinetics of the various loss processes from the well plates, this model was chosen realizing that there is often one rate limiting step determining the overall loss kinetics. Care should however be taken when interpreting the empirical rate constant $k$ of these loss kinetics.

Experimental octanol-water partition ratios, $\log K_{\mathrm{ow}}$, were found in the Danish (Q)SAR database $^{32}$ for all the chemicals and air-water partition ratios at $35-37^{\circ} \mathrm{C}, \log K_{\mathrm{aw}}$, were calculated from literature values of Henry's law constants at the relevant temperature or estimated by EPI HenryWin (EPIWEB 4.1) (see supporting information S1), and were used for plotting of the results. 


\section{Results}

Free fractions. The free fraction $(f f)$ of the test chemicals in each medium was determined based on fits of equation 10 to dilution plots as illustrated in Figure 2A. In supporting information S2, dilution plots are shown for all chemicals and all three media.

The ffs are shown in Table 1, and range from $<1 \%$ to $100 \%$. The differences in $f f s$ were larger between chemicals than between media. For nearly all chemicals ffs were slightly lower in the $2 \%$ cs-FBS medium than in the serum free $1 \% \mathrm{~N} 2$-supplement medium. ffs in the $10 \%$ FBS medium were sometimes lower than in the two other media, but even though not expected based on the higher content of proteins and lipids in the $10 \%$ FBS, ffs were also sometimes measured to be higher.

The $f f$ in the $10 \%$ FBS medium is plotted as a function of $\log K_{\text {ow }}$ in Figure $2 \mathrm{~B}$ and Supporting Information S3 shows ff in the other two media. Two distinct regions are seen on the plots. For chemicals with a $\log K_{\text {ow }}$ below 3.5, the $f f$ was above $30 \%$ and independent of the $\log K_{\text {ow }}$ of the chemical. For chemicals with a $\log K_{\text {ow }}$ above 3.5, the $f f$ was clearly dependent on the $\log K_{\text {ow. }}$ A linear regression of the $\log f f$ against $\log K_{\text {ow }}$ for chemicals with a $\log K_{\text {ow }}$ above 3.5 is shown in Figure 2B. The slope of the regression was $-0.96 \pm 0.19$ in the $10 \%$ FBS medium, $-0.83 \pm 0.10$ in the $2 \%$ cs-FBS medium and $-0.97 \pm 0.23$ in the $1 \% \mathrm{~N} 2$ supplement medium. 

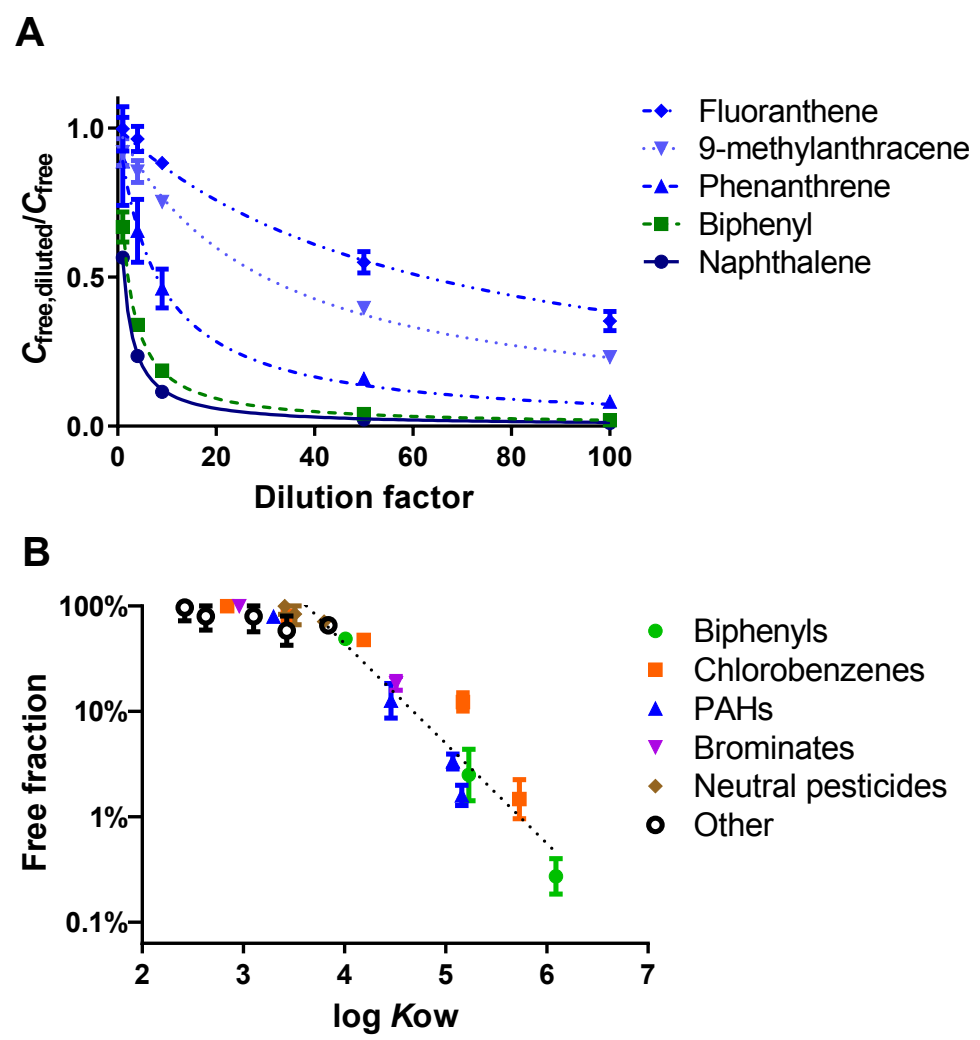

Figure 2. A) Dilution series of five chemicals in the medium containing $10 \%$ FBS. Error bars show standard error of mean $(n=3)$. B) Free fraction of the test chemicals in the $10 \%$ FBS medium. The dotted line shows the linear regressions between $\log$ free fraction and $\log K_{\mathrm{ow}}$ for chemicals with $\log K_{\text {ow }}$ above 3.5 . Error bars show 95\% confidence limits on the free fraction determination from the fit of equation 10 to the dilution series. If absent, error bars are smaller than the symbol size. 
Table 1. Free fractions of the test chemicals in three in vitro media and $95 \%$ confidence limits on the free fractions.

$10 \%-F B S$ medium $\quad 2 \%$ cs-FBS medium $\quad 1 \%$ N2 suppl. medium

\begin{tabular}{|c|c|c|c|}
\hline \multicolumn{4}{|l|}{ Biphenyls: } \\
\hline Biphenyl & $49 \%(44-55 \%)$ & $29 \%(25-33 \%)$ & $51 \%(44-60 \%)$ \\
\hline РCB15 & $2.5 \%(1.4-4.4 \%)$ & $3.9 \%(2.2-6.9 \%)$ & $3.3 \%(1.3-8.3 \%)$ \\
\hline PCB52 & $0.27 \%(0.18-0.4 \%)$ & $\mathbf{0 . 6 \%}(0.21-1.75 \%)$ & \\
\hline \multicolumn{4}{|l|}{ Chlorobenzenes: } \\
\hline Chlorobenzene & $100 \%(89-100 \%)$ & $50 \%(43-58 \%)$ & $54 \%(49-59 \%)$ \\
\hline 1,4-dichlorobenzene & $81 \%(75-87 \%)$ & $31 \%(27-34 \%)$ & $46 \%(44-48 \%)$ \\
\hline 1,3,5-trichlorobenzene & $48 \%(45-51 \%)$ & $27 \%(23-32 \%)$ & $43 \%(42-45 \%)$ \\
\hline Pentachlorobenzene & $12 \%(10-15 \%)$ & $5.8 \%(3.9-8.8 \%)$ & $7.7 \%(4.8-12 \%)$ \\
\hline Hexachlorobenzene & $1.5 \%(1.0-2.3 \%)$ & $2.3 \%(1.5-3.4 \%)$ & $4.3 \%(3.2-5.7 \%)$ \\
\hline \multicolumn{4}{|l|}{ PAHs: } \\
\hline Naphthalene & 79\% (75-83\%) & $34 \%(30-38 \%)$ & $56 \%(53-59 \%)$ \\
\hline Phenanthrene & $13 \%(9-18 \%)$ & $18 \%(15-22 \%)$ & $24 \%(18-32 \%)$ \\
\hline 9-Methylanthracene & $3.4 \%(2.8-4.0 \%)$ & $4.2 \%(1.9-9.1 \%)$ & $4.2 \%(1.6-11 \%)$ \\
\hline Fluoranthene & $1.6 \%(1.3-2.0 \%)$ & $2.7 \%(1.1-6.6 \%)$ & $4.3 \%(2.3-7.9 \%)$ \\
\hline Benz(a)anthracene & $<0.1 \%$ & $<0.1 \%$ & $\mathbf{0 . 2 6 \%}(0.08-0.91 \%)$ \\
\hline \multicolumn{4}{|l|}{$\begin{array}{l}\text { Brominated } \\
\text { structures: }\end{array}$} \\
\hline $\begin{array}{l}\text { 1,2-dibromo-3- } \\
\text { chlorpropane }\end{array}$ & $100 \%(94-100 \%)$ & $86 \%(77-95 \%)$ & $86 \%(83-90 \%)$ \\
\hline 1,3,5-tribromobenzene & $19 \%(16-22 \%)$ & $16 \%(13-22 \%)$ & $29 \%(22-38 \%)$ \\
\hline \multicolumn{4}{|l|}{ Neutral pesticides: } \\
\hline Chlorpropham & $84 \%(67-100 \%)$ & $100 \%(88-100 \%)$ & $100 \%(59-100 \%)$ \\
\hline Lindane & $71 \%(63-81 \%)$ & $86 \%(80-93 \%)$ & $100 \%(81-100 \%)$ \\
\hline Nitrapyrin & $100 \%(84-100 \%)$ & $85 \%(71-100 \%)$ & $95 \%(71-100 \%)$ \\
\hline \multicolumn{4}{|l|}{ Other structures: } \\
\hline Benzo[h]quinoline & $58 \%(42-80 \%)$ & $86 \%(77-96 \%)$ & $100 \%(73-100 \%)$ \\
\hline Chlorocresol & $80 \%(57-100 \%)$ & $85 \%(69-100 \%)$ & $100 \%(52-100 \%)$ \\
\hline Diethylphthalate & $97 \%(73-100 \%)$ & $97 \%(77-100 \%)$ & $100 \%(55-100 \%)$ \\
\hline$\beta$-Ionone & $65 \%(61-71 \%)$ & $38 \%(34-42 \%)$ & $65 \%(53-81 \%)$ \\
\hline $\begin{array}{l}N \text {-Nitrosodi- } n \text { - } \\
\text { butylamine }\end{array}$ & $80 \%(59-100 \%)$ & $95 \%(69-100 \%)$ & $100 \%(86-100 \%)$ \\
\hline
\end{tabular}

Losses due to sorption and evaporation. Phenanthrene losses from well plates and measurements of test chemicals in adjacent wells containing non-spiked medium (crossover) are shown in Figure 3. Loss curves for all the chemicals are shown in supporting information S4. 


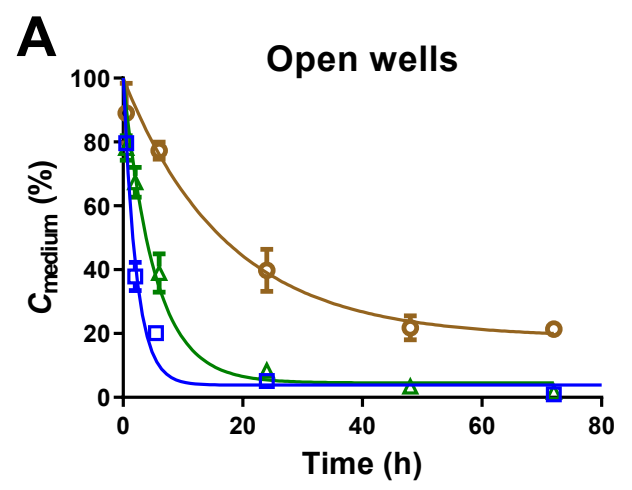

B

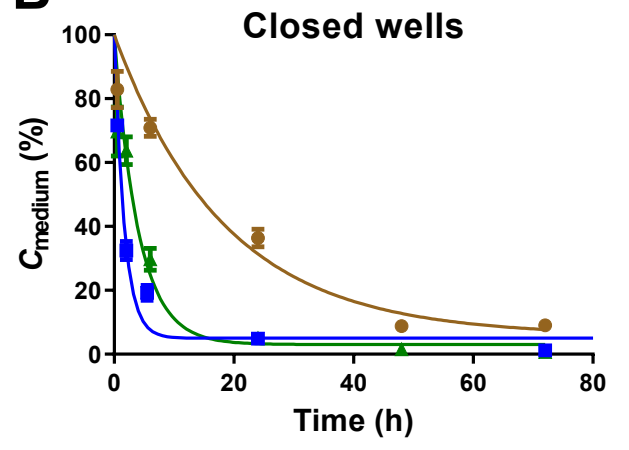

C Non-spiked open wells

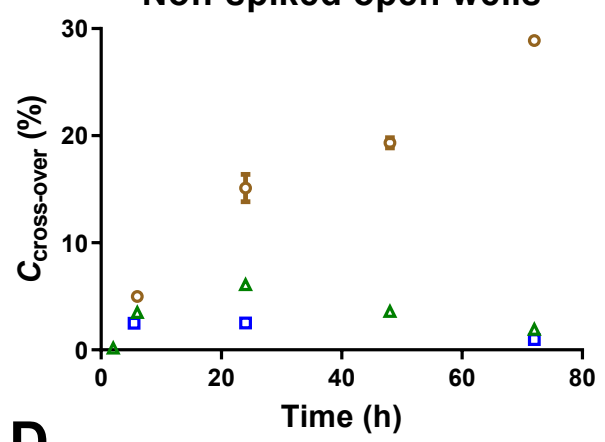

Don-spiked closed wells

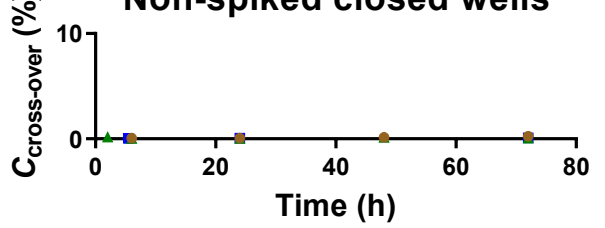

- $10 \%$ FBS medium, open

- $10 \%$ FBS medium, closed

$\Delta \quad 2 \%$ cs-FBS medium, open

- $2 \%$ cs-FBS medium, closed

- $1 \% \mathrm{~N} 2$-supplement, open

- $1 \% \mathrm{~N} 2$-supplement, closed 
Figure 3. Loss curves for Phenanthrene $\left(\log K_{\text {ow }}: 4.46\right.$ and $\left.\log K_{\text {aw }}:-2.5\right)$ determined by equation 11 and fitted to equation 13 in three types of spiked medium in A) open wells and B) closed wells; the concentrations of Phenanthrene in adjacent non-spiked wells determined from equation 12 , corresponding to percentage of $C_{\text {medium }}$ at time $\mathrm{t}=0$ for $\mathrm{C}$ ) open wells and D) closed wells. Error bars show SE, $n=3$ for open and closed wells and $n=2$ for crossover.

The loss curves for the model compound phenanthrene illustrate the effects seen for the other chemicals. Generally, the concentration decreased more and faster in the 1\% N2-supplement medium than in the $2 \%$ cs-FBS medium and slowest in the $10 \%$ FBS medium, which had the highest concentration of lipids and proteins. For most of the chemicals tested in this experiment, the losses during the 3-5 days incubation were substantial and similar in the open and closed wells. Losses were slightly lower in the closed wells compared to the open wells for the chemicals in the upper part of the $K_{\text {aw }}$ range, and slightly higher for chemicals in the upper part of the $K_{\text {ow }}$ range (as seen for Phenanthrene in the 10\% FBS medium in Figure 3A and 3B).

During incubation, the concentration in spiked and non-spiked open wells approached each other for most chemicals except the 4 and 5 ringed PAHs, due to their high $K_{\text {ow }}$ (i.e. high binding to medium constituents and plastic wall) and low $K_{\text {aw }}$ (i.e. limited air water partitioning). This crossover was clearly caused by a mass transfer via the headspace of the well plates, since the concentrations in the closed non-spiked wells did not increase similarly. In some cases, the losses of chemicals out of the well plates were so fast, that the concentration in the non-spiked wells only slightly increased before decreasing again (as seen in Figure 3c, 1\% N2-supplement). In some cases, equilibrium between the open spiked and open non-spiked wells was reached before the incubation stopped resulting in similar and decreasing concentrations in all wells during the rest of the incubation (e.g. Figure 3c, 2\% cs-FBS medium). In other cases the evaporative losses 
were slower than the above examples, and significant concentrations were found in the nonspiked wells at the end of the test (e.g. Figure 3c, 10\% FBS medium). For phenanthrene, the crossover was seen to increase with increased serum content of the medium. This can be explained by a higher sorptive capacity of the medium with higher serum content, and the nonspiked wells thereby served as a sorptive sink.

Benz(a)anthracene was the only chemical not detected in the open non-spiked wells while still at high concentrations in the spiked well on day 3, while dicofol and fluoranthene showed only very slight increases in the non-spiked wells. Generally, crossover was significantly reduced in the closed wells. $N$-nitrosodi- $n$-butylamine, was the only chemical detected in the closed nonspiked wells at substantial concentrations (5-10\% after 3-5 days).

The test substance losses after 24 hours incubation is plotted in the chemical space of the airwater and octanol water partition ratio in Figure 4. In Supporting Information S5, the crossover to neighboring wells is likewise shown in this chemical space. The figure reveals that chemicals with a $\log K_{\text {aw }}$ above -3 and a $\log K_{\text {ow }}$ below 4 were lost from the well plates independently of the medium used. A medium effect was seen on the losses for chemicals with a log $K_{\text {ow }}$ above 4 . Extensive losses were seen from the 1\% N2-supplement medium, intermediate losses were seen from the $2 \%$ cs-FBS medium whereas the chemicals with a $\log K_{\text {aw }}$ below -2 were retained more than $50 \%$ in the $10 \%$ FBS medium. Below a $\log K_{\text {aw }}$ of -3.5 and a $\log K_{\text {ow }}$ of 4 , chemicals were retained in the test media $(>50 \%)$, however high crossover to neighboring wells were seen for these chemicals $(>5 \%)$. 

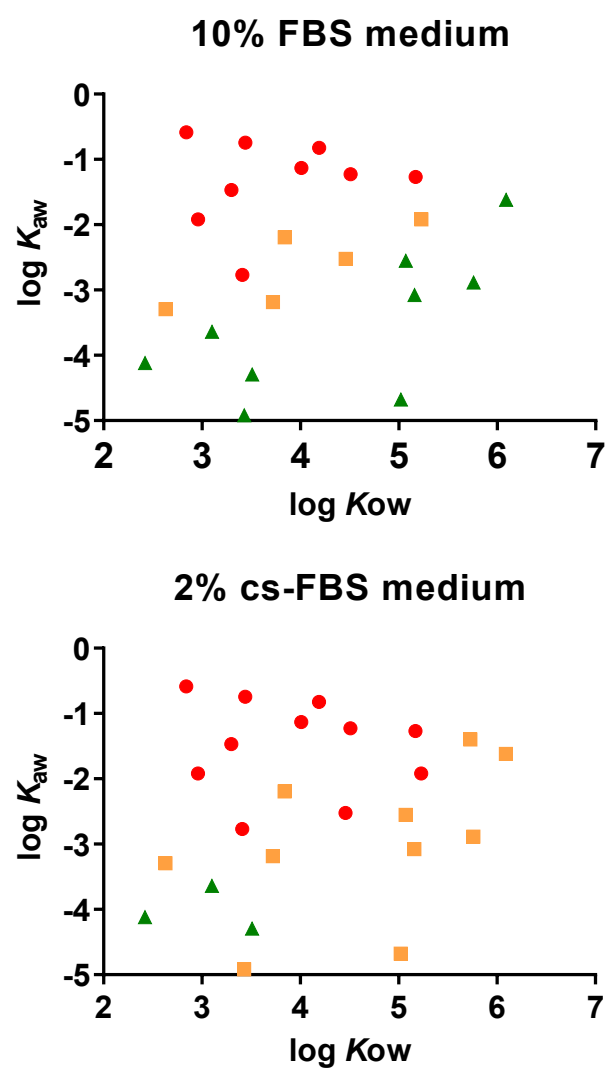

$1 \%$ N2 supplement medium

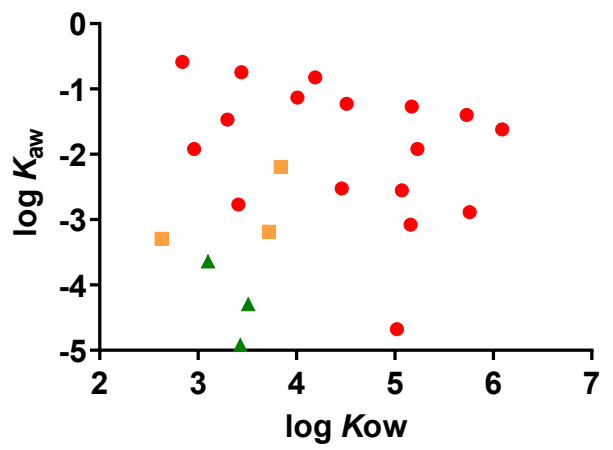

Losses after $24 \mathrm{~h}$ :

- $>90 \%$

- $50-90 \%$

$\Delta<50 \%$

Figure 4. Test substance losses from 96 -well plates after 24 hours incubation at $37^{\circ} \mathrm{C}$ distributed in the chemical space of air water partition ratio at $37^{\circ} \mathrm{C}, \log K_{\mathrm{aw}}$, and octanol-water partition ratio, $\log K_{\mathrm{ow}}$. 
Freely dissolved concentrations. Based on the measured free fractions and the fitted loss curves, the $C_{\text {free }}$ in the well plates were calculated and are shown for eight chemicals in Figure 5 and for all chemicals in Supporting Information S6. In Figure 5, the plots are situated roughly according to the chemical space i.e. the most sorptive chemicals to the right and the most volatile chemicals on the top row. Nominal concentrations are listed below the heading. The largest differences between the nominal concentrations and the $C_{\text {free }}$ were found for the chemicals in the top right corner of the figure, and the largest effect of increasing serum concentration in the medium was seen for the chemicals with highest $\log K_{\text {ow }}$, PCB52 and fluoranthene. Increasing the serum content of the medium did not markedly affect the losses for the less sorptive and volatile chemicals 1,2-dibromo-3-chloropropane and nitrapyrin (top left in Figure 5).
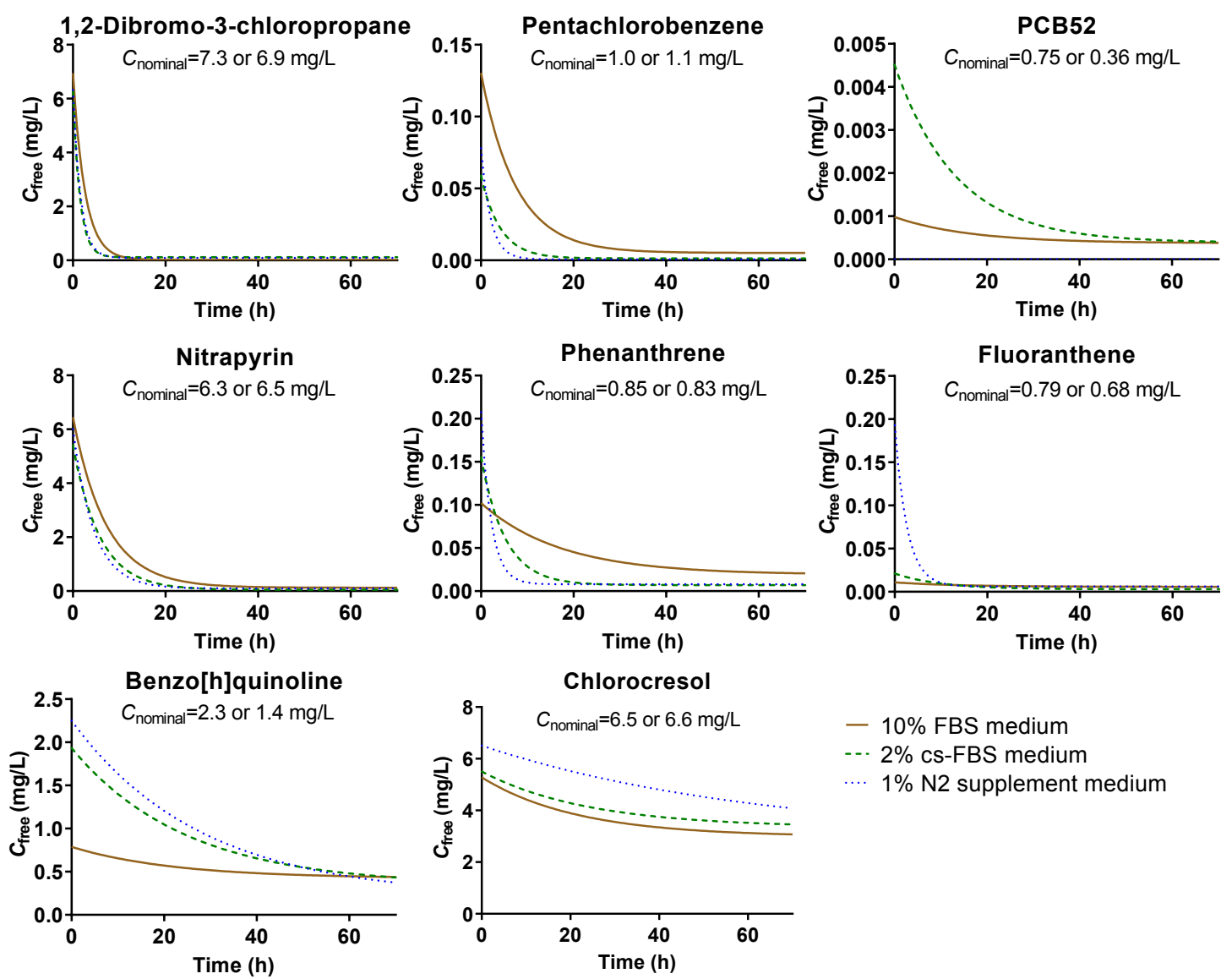

- $10 \%$ FBS medium

-.. $2 \%$ cs-FBS medium

… $1 \%$ N2 supplement medium 
Figure 5. Freely dissolved concentrations of eight test chemicals in open well plates for three types of spiked medium. Two nominal concentrations are listed, the first for the $2 \%$ cs-FBS medium and 1\% N2-supplement medium and the second for the 10\% FBS medium.

\section{Discussion}

Medium binding. The relationship between $\log K_{\mathrm{ow}}$ and $f f$ showed the same pattern in all three media: a small decrease in $\log f f$ for chemicals with $\log K_{\text {ow }}$ below 3-4 followed by a linear decrease in $\log f f$ for chemicals with $\log K_{\text {ow }}$ between 4 and 7 . This pattern for binding to serum was also seen in medium-water partition ratios ${ }^{6}$ modeled based on lipid and protein binding 33,34 (Note the relationship between medium-water partition ratios, $K_{\text {medium,water, and } f f: \log K_{\text {medium,water }}}$ $=\log \left(f f^{1}\right)$; therefore a linear increase in $\log K_{\text {medium,water }}$ corresponds to a linear decrease in $\log$ $f f$ ). The $f f$ s found in this study (at $37^{\circ} \mathrm{C}$ ) were however slightly higher than the $f f$ s estimated by Fischer et al. ${ }^{6}$ (at $21^{\circ} \mathrm{C}$ ) and measured by Kramer et al. ${ }^{1}$ (at $20^{\circ} \mathrm{C}$ ). As an example, Kramer et al. ${ }^{1}$ found free fractions in the medium (calculated the as measured free divided by the measured medium concentrations) of $5.7 \%$ and $11 \%$ for phenanthrene in medium containing 5 and $2 \%$ FBS respectively, and in this study free fractions of phenanthrene were $13 \%$ and $18 \%$ in medium containing $10 \%$ FBS and $2 \%$ cs-FBS respectively. Some variation in the composition and thereby also binding properties of FBS can be expected between different batches, and the temperature can also affect sorption to medium constituents. Jonker et al., ${ }^{35}$ e.g. observed a decrease in silicone rubber-water partition ratios with increasing temperature.

Medium binding has two effects in a bioassay. Firstly, it reduces the actual exposure of hydrophobic chemicals in in vitro tests by lowering the $C_{\text {free }}$ of the chemicals and thereby also their chemical activity and internal concentrations in the cells. This is the reason why Gülden et 
al. ${ }^{22}$ found it important to consider binding to lipids and proteins for chemicals with $\log K_{\mathrm{ow}}$ above 2 when extrapolating effect concentrations from in vitro to in vivo. The current study found medium binding important above a $\log K_{\mathrm{ow}}$ of 3-4 as also found by Riedl and Altenburger. ${ }^{36}$

The second effect of medium binding in bioassays is that it reduces sorptive losses to well plate plastic and volatile losses. It has been shown that the reduction in losses caused by medium binding can be used as a buffer to stabilize the concentrations in the tests. ${ }^{6,37}$ Fischer et al. termed this approach 'serum mediated passive dosing' ${ }^{6}$ Schirmer et al. ${ }^{38}$ found medium concentrations of fluoranthene in 12 well microplates after 24 hours incubation at $22^{\circ} \mathrm{C}$ to remain at $70 \%$ of nominal concentrations when using $10 \%$ FBS in the medium but only $8 \%$ in the culture medium without FBS. Similar results were seen in the current study with total medium fluoranthene concentrations of $63 \%$ in open wells containing the $10 \%$ FBS medium and $7 \%$ in wells containing the $1 \% \mathrm{~N} 2$-supplemented medium without serum after 24 hours of incubation at $37^{\circ} \mathrm{C}$.

At serum concentrations of $10 \%$, the serum acted as a buffer-compartment and retained chemicals with a $\log \mathrm{K}_{\mathrm{ow}}$ of 5 and above in the test medium. Even for these highly hydrophobic chemicals, it was still important that the volatility was below a certain level, which increased with increasing hydrophobicity (see Figure 4). Further, the buffering effect of the medium resulted in markedly lower $C_{\text {free }}$ than medium concentrations.

Similar to the effects of medium binding, hydrophobic constituents sorb to cells in in vitro tests. ${ }^{1}$ If the binding is substantial, it may reduce volatile losses and sorptive losses to well plate plastic, and reduce the test concentration in the medium. 
Sorptive and volatile losses from multiwell plates. Two major loss processes were expected for the multiwell plates; volatilization and sorption to the well plate plastic. The data supports this since losses increased with increasing $K_{\text {aw }}$ and $K_{\text {ow }}$ (Figure 4).

The studies reporting losses from well plates referenced below used incubation temperatures of $19-21^{\circ} \mathrm{C}$, which is much lower than the $37^{\circ} \mathrm{C}$ used in the current study. Tanneberger et al. ${ }^{39}$ e.g. found less than $10 \%$ of the applied 1,2-dichlorobenzene in serum-free medium after $24 \mathrm{~h}$ incubation at $19^{\circ} \mathrm{C}$ in 24 well microplates. In our study less than $1 \%$ of 1,4-dichlorobenzene was found in the N2-supplemented medium after $24 \mathrm{~h}$ incubation at $37^{\circ} \mathrm{C}$. The higher losses of this semi-volatile chemical in the current study can be explained by higher evaporative losses at a higher incubation temperature.

Chemicals with relatively high $K_{\text {aw }}$ and $K_{\text {ow }}\left(\log K_{\text {aw }}\right.$ in the range -0.9 to -3.4 and $\log K_{\text {ow }}$ around 3) were lost very quickly from the well plates, and the use of aluminum microplate sealing tape to close the wells only slightly slowed the losses. The losses were much higher than expected sorptive losses, ${ }^{6}$ indicating that the sealing tape did not prevent volatile losses of these test chemicals: $<3 \%$ of naphthalene and 1,3,5-trichlorobenzene were found in the medium in the closed wells after 24 hours incubation. Similar high losses were seen by Stadnicka-Michalak et al. ${ }^{7}$ in 24-well microplates covered with plastic foil and incubated at $19^{\circ} \mathrm{C}$. They found 6 and $13 \%$ of 1,2,3-trichlorobenzene and naphthalene in the medium after 24 hours incubation, but less than $40 \%$ extracted from the well plate plastic, plastic foil and cells. This indicates significant losses out of the system for the two volatile chemicals even at $19^{\circ} \mathrm{C}$ despite the coverage by plastic foil. 
For a more sorptive chemical, hexachlorobenzene, Stadnicka-Michalak et al. ${ }^{7}$ found $2 \%$ and $8 \%$ left in medium with cells in duplicate measurements after 24 hours incubation at $19^{\circ} \mathrm{C}$ covered with plastic foil. This corresponds well with the $2-4 \%$ left after 24 hours in the open and closed well of the N2-supplement medium in this study. In their study, a fraction of the chemical was sorbed to cells, and in our study volatilization was probably higher due to the higher incubation temperature $\left(37^{\circ} \mathrm{C}\right)$.

Phenanthrene is semi-volatile, and has $\log K_{\text {ow }}$ of $\sim 4.5$. When comparing the total phenanthrene losses after 48 hours seen in this study at $37^{\circ} \mathrm{C}(91 \%$ and $98 \%$ in closed wells for $10 \%$ FBS medium and $2 \%$ cs-FBS medium, respectively) to the total losses (volatile, plastic sorption and cell sorption) measured by Kramer et al. ${ }^{1}$ at $20^{\circ} \mathrm{C}(15 \%$ and $27 \%$ for $5 \%$ FBS medium and $2 \%$ FBS medium, respectively), it is evident that the losses of phenanthrene were much larger in the current study. For comparative reasons, sorption to the cells in the study by Kramer et al. ${ }^{1}$ were here seen as losses (from the medium), since cells were not included in our study. Even though cell sorption increase losses from the medium, they may however buffer other loss processes resulting in a reduced effect on total losses. As discussed above, the increased temperature leads to increased volatile losses. The temperature effect on sorptive losses is less straightforward. Increased temperatures lead to a decrease in partition ratios to medium constituents and plastic, but also to faster diffusion of the chemicals in the plastic. The enhanced diffusion in the plastic may therefore lead to overall higher sorptive losses at higher temperatures, even though the partition ratio to plastic decreases. The study by Kramer et al., ${ }^{1}$ was conducted in 24 well plates with a larger volume than the 96 well plates used in this study. The plastic surface area to medium volume ratio was therefore higher in the current study, increasing the plastic sorption. Furthermore, the aluminum foil used for closing the wells in the study by Kramer et al. ${ }^{1}$ did not 
contain any adhesive, whereas the foil used in this study contained an acrylic adhesive, which could increase the losses due to sorption to the glue.

Other loss processes. Losses were for some of the more hydrophobic chemicals slightly larger in the closed wells than in the open wells. This effect could be explained by a combination of two factors. Sorption to the glue on the aluminum cover could have increased the sorptive losses in the closed wells compared to the open wells with no cover. The volume of medium in the open well plates was also reduced a bit during incubation due to evaporation ( $9 \%$ in 72 hours), increasing the concentrations in the wells slightly.

Chemicals would normally not be expected to be able to crossover from one well to the next when the wells are closed. Recently, measured diffusion coefficients for $>20$ chemicals $\left(\mathrm{D}_{\mathrm{PS}}\right.$ in the range $10^{-16}-10^{-15} \mathrm{~m}^{2} \mathrm{~s}^{-1}$ ) showed very slow diffusion in polystyrene at $21^{\circ} \mathrm{C}$, with diffusion distances of 5-20 $\mu \mathrm{m}$ in 96 hours $^{6}$ - well below the thickness of the well walls. In our study, $n$ nitrosodi- $n$-butylamine was however found in the closed non-spiked wells at multiple timepoints in all three media. Even with a markedly different diffusion of $n$-nitrosodi- $n$-butylamine in polystyrene at $37^{\circ} \mathrm{C}$, the chemical would have to pass two well walls to reach the non-spiked wells, which is not likely. Another route of transfer to enter the non-spiked wells is diffusion through the glue attaching the aluminum foil to the well-plate or through microscopic openings in the interface between the well plate, glue and aluminum foil. However, further studies are needed to confirm and investigate this observation.

Implications for toxicity testing. This study introduced a new approach for determining time resolved exposure within toxicity testing for volatile and semi-volatile hydrophobic neutral organic chemicals. The approach provided measurements of free fractions $(f f)$ and time resolved 
total concentrations $\left(C_{\text {total }}(\mathrm{t})\right)$, which then were combined to determine time resolved freely dissolved concentrations $\left(C_{\text {free }}(\mathrm{t})=C_{\text {total }}(\mathrm{t}) \times f f\right)$. The methodology allows thus further assessments of toxicity data on a $C_{\text {free }}$ as well as on a $C_{\text {total }}$ basis.

The losses and crossover were substantial for most test chemicals when incubated in 96 well plates at $37^{\circ} \mathrm{C}$, which questions the use of such multi-well plates for in vitro testing of semivolatile and hydrophobic chemicals. Additionally, the results underline the importance of actually measuring exposure concentrations during in vitro assays, while aiming for a defined and constant exposure during the test. We envisage grouping chemicals into three bins. 1) Losses of $<20 \%$ and cross-over of less than $2 \%$ mean that exposure concentrations are controlled in treatment wells and close to zero in the blank wells. This can be taken as an initial exposure validity criterion. 2) Moderate test substance losses e.g. 20-50\% may allow simple corrections, for instance by measuring the initial and final concentration and then using the average for the dose-response fittings. ${ }^{12}$ 3) Large test substance losses of e.g. $>50 \%$ question the validity of the test results (e.g. for tests spiked with a factor of 2 between each test concentrations). In this case, the presented method may help to assess published data and be used as validity criteria for future testing.

The critical areas for losses and crossover are illustrated in Figure 6. For a 24 hour test, 3 chemicals with a $\log K_{\text {ow }}$ below 4 and $\log K_{\text {aw }}$ below -3.5 were seen to have losses $<50 \%$ in all three media. However, the chemicals in this study that met these criteria showed high crossover to the neighboring wells. The only chemicals with losses $<50 \%$ and crossover $<2 \%$ were found in the $10 \%$ FBS medium and had $\log K_{\mathrm{ow}}>5$ and $\log K_{\mathrm{aw}}<-2.5$. If the serum content is increased, chemicals with a higher $\log K_{\mathrm{ow}}$ can therefore be tested without too high losses and crossover provided that the $\log K_{\mathrm{aw}}$ is not too high. 


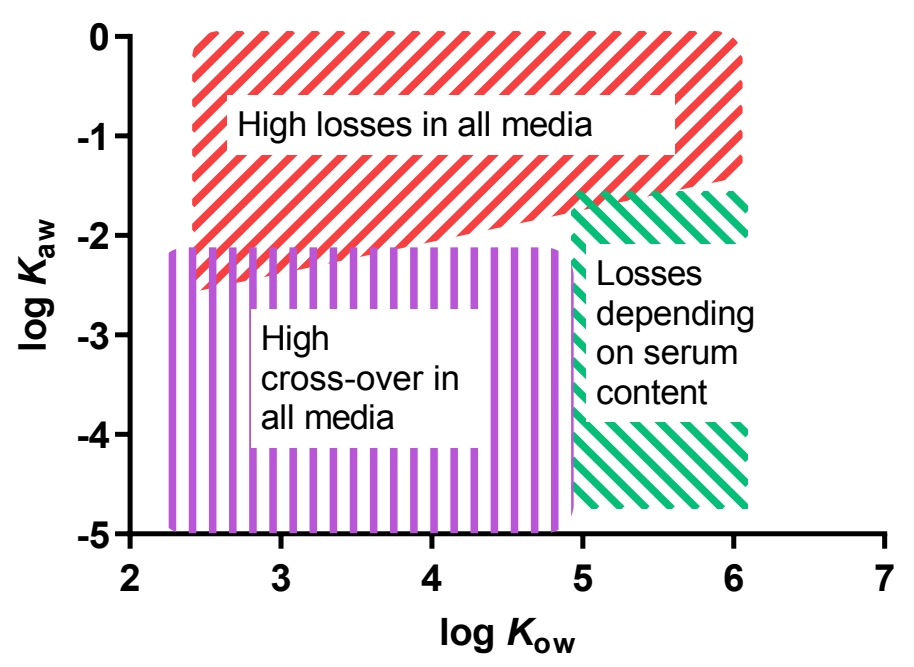

Figure 6. Air-water and octanol-water partition ratios associated with high losses and high crossover in 96 well in vitro assays incubated at $37^{\circ} \mathrm{C}$ for 24 hours.

In vitro tests are often conducted to establish the causal relationship between exposure to a chemical and its toxicity. The exposure is then considered to be the independent or controlled variable, whereas toxicity is the dependent variable. However, the present study clearly demonstrates rapidly decreasing exposure for semi-volatile and hydrophobic test chemicals during the test incubation, and in vitro exposure then becomes a poorly controlled variable. Even more dramatic decreases are expected in 384 and 1536 well plates used in high throughput testing due to their higher surface-to-volume ratios. This means that the validity of results from high-throughput screening programs such as the ToxCast program (which e.g. includes all of the neutral pesticides and PAH's used in this study) and Tox21 program (which e.g. includes chlorobenzenes $),{ }^{40}$ needs to be reconsidered based on the physicochemical properties of the test chemicals.

Future research and development should now be directed to find test systems, dosing systems and test methodology that provide a more constant and better controlled in vitro exposure. The 
further development and selection of better test systems might be inspired by developments within aquatic biodegradation and toxicity testing with bacteria and microalgae, where similar challenges have been solved by converting open tests into closed-vial formats. ${ }^{30,41,42}$ Exposure confirmation based on analytical measurements will then be instrumental to confirm stable exposure and if necessary to correct for minor losses. Finally, such exposure control measures and exposure confirmation data should also be included in good in vitro reporting standards. ${ }^{43}$

\section{Corresponding Author}

* Department of environmental engineering, Technical University of Denmark, Bygningstorvet, Building 115, 2800 Kgs. Lyngby, Denmark. Tel. +45 45251600. hbir@env.dtu.dk.

\section{Author Contributions}

The manuscript was written through contributions of all authors. All authors have given approval to the final version of the manuscript.

\section{Funding Information}

Mainly CEFIC Long-Range Research Initiative (LRI), project ECO36, and additionally the National Centre for the Replacement, Refinement and Reduction of Animals in Research (NC3Rs) (Crack-it Challenge 27: DoCE).

\section{Acknowledgements}

The authors thank the CEFIC Long-Range Research Initiative (LRI), project ECO36, for the financial support and the National Centre for the Replacement, Refinement and Reduction of Animals in Research (NC3Rs) for additional funding (Crack-it Challenge 27: DoCE). We thank Beate Escher, Joop Hermens, Luise Henneberger, Todd Gouin, Jon Arnot, Martijn Rooseboom, 
Reinhard Kreiling, Chris Sparham, Antony Williams, Ellen Fritsche and Stefan Masjosthusmann

for fruitful discussions and input. We thank Hanne Bøggild for laboratory support.

Supporting Information. Dilution curves used to determine the free fraction, free fraction plotted as a function of $\log K_{\mathrm{ow}}$, loss curves for well plates, and time resolved $C_{\text {free. }}$.

The files are available free of charge.

\author{
Abbreviations list \\ $D F$ : Dilution factor \\ $E$ : Enhanced capacity \\ $f f:$ Free fraction \\ FBS: Fetal bovine serum \\ HS-SPME: Headspace solid-phase microextraction \\ $K_{\text {aw }}$ : Air water partition ratio \\ $K_{\text {ow }}$ : Octanol water partition ratio \\ $K_{\text {medium,water: }}$ Medium water partition ratio
}

PAHs: Poly aromatic hydrocarbons

PCBs: Poly chlorinated biphenyls

SPME: Solid phase microextraction

SVHOCs: semi-volatile and hydrophobic organic chemicals 


\section{References}

(1) Kramer, N. I.; Krismartina, M.; Rico-Rico, Á.; Blaauboer, B. J.; Hermens, J. L. M. Quantifying Processes Determining the Free Concentration of Phenanthrene in Basal Cytotoxicity Assays. Chem. Res. Toxicol. 2012, 25 (2), 436-445.

(2) Groothuis, F. A.; Heringa, M. B.; Nicol, B.; Hermens, J. L. M.; Blaauboer, B. J.; Kramer, N. I. Dose Metric Considerations in in Vitro Assays to Improve Quantitative in Vitro-in Vivo Dose Extrapolations. Toxicology 2015, 332, 30-40.

(3) Stalter, D.; Dutt, M.; Escher, B. I. Headspace-Free Setup of in Vitro Bioassays for the Evaluation of Volatile Disinfection By-Products. Chem. Res. Toxicol. 2013, 26 (11), $1605-1614$.

(4) Liu, F. F.; Escher, B. I.; Were, S.; Duffy, L.; Ng, J. C. Mixture Effects of Benzene, Toluene, Ethylbenzene, and Xylenes (BTEX) on Lung Carcinoma Cells via a Hanging Drop Air Exposure System. Chem. Res. Toxicol. 2014, 27 (6), 952-959.

(5) Beresford, N.; Routledge, E. J.; Harris, C. A.; Sumpter, J. P. Issues Arising When Interpreting Results from an in Vitro Assay for Estrogenic Activity. Toxicol. Appl. Pharmacol. 2000, 162 (1), 22-33.

(6) Fischer, F. C.; Cirpka, O. A.; Goss, K.-U.; Henneberger, L.; Escher, B. I. Application of Experimental Polystyrene Partition Constants and Diffusion Coefficients to Predict the Sorption of Neutral Organic Chemicals to Multiwell Plates in in Vivo and in Vitro Bioassays. Environ. Sci. Technol. 2018, 52 (22), 13511-13522.

(7) Stadnicka-Michalak, J.; Tanneberger, K.; Schirmer, K.; Ashauer, R. Measured and Modeled Toxicokinetics in Cultured Fish Cells and Application to in Vitro - In Vivo Toxicity Extrapolation. PLoS One 2014, 9 (3).

(8) Hestermann, E. V; Stegeman, J. J.; Hahn, M. E. Serum Alters the Uptake and Relative Potencies of Halogenated Aromatic Hydrocarbons in Cell Culture Bioassays. Toxicol. Sci. 2000, 53 (2), 316-325. 
(9) Kramer, N. I.; Busser, F. J. M.; Oosterwijk, M. T. T.; Schirmer, K.; Escher, B. I.; Hermens, J. L. M. Development of a Partition-Controlled Dosing System for Cell Assays. Chem. Res. Toxicol. 2010, 23 (11), 1806-1814.

(10) Dupraz, V.; Stachowski-Haberkorn, S.; Wicquart, J.; Tapie, N.; Budzinski, H.; Akcha, F. Demonstrating the Need for Chemical Exposure Characterisation in a Microplate Test System: Toxicity Screening of Sixteen Pesticides on Two Marine Microalgae. Chemosphere 2019, 221, 278-291.

(11) Gellert, G.; Stommel, A. Influence of Microplate Material on the Sensitivity of Growth Inhibition Tests with Bacteria Assessing Toxic Organic Substances in Water and Waste Water. Environ. Toxicol. 1999, 14 (4), 424-428.

(12) Tanneberger, K.; Knöbel, M.; Busser, F. J. M.; Sinnige, T. L.; Hermens, J. L. M.; Schirmer, K. Predicting Fish Acute Toxicity Using a Fish Gill Cell Line-Based Toxicity Assay. Environ. Sci. Technol. 2013, 47 (2), 1110-1119.

(13) Natsch, A.; Laue, H.; Haupt, T.; von Niederhäusern, V.; Sanders, G. Accurate Prediction of Acute Fish Toxicity of Fragrance Chemicals with the RTgill-W1 Cell Assay. Environ. Toxicol. Chem. 2018, 37 (3), 931-941.

(14) OECD. Test No. 236: Fish Embryo Acute Toxicity (FET) Test; OECD Publishing: Paris, 2013; Vol. Section 2.

(15) ISO21115. Water Quality - Determination of Acute Toxicity of Water Samples and Chemicals to a Fish Gill Cell Line (RTgill-W1). International Organization for Standardization: Geneva 2019.

(16) Smith, K. E. C.; Schäfer, S. Defining and Controlling Exposure During In Vitro Toxicity Testing and the Potential of Passive Dosing. Adv. Biochem. Eng. Biotechnol. 2017, 157, $263-292$.

(17) Smith, K. E. C.; Oostingh, G. J.; Mayer, P. Passive Dosing for Producing Defined and Constant Exposure of Hydrophobic Organic Compounds during in Vitro Toxicity Tests. Chem. Res. Toxicol. 2010, 23, 55-65. 
(18) Smith, K. E. C.; Heringa, M. B.; Uytewaal, M.; Mayer, P. The Dosing Determines Mutagenicity of Hydrophobic Compounds in the Ames II Assay with Metabolic Transformation: Passive Dosing versus Solvent Spiking. Mutat. Res. Toxicol. Environ. Mutagen. 2013, 750 (1-2), 12-18.

(19) Gilbert, D.; Mayer, P.; Pedersen, M.; Vinggaard, A. M. Endocrine Activity of Persistent Organic Pollutants Accumulated in Human Silicone Implants - Dosing in Vitro Assays by Partitioning from Silicone. Environ. Int. 2015, 84, 107-114.

(20) Oostingh, G. J.; Smith, K. E. C.; Tischler, U.; Radauer-Preiml, I.; Mayer, P. Differential Immunomodulatory Responses to Nine Polycyclic Aromatic Hydrocarbons Applied by Passive Dosing. Toxicol. Vitr. 2015, 29 (2), 345-351.

(21) Armitage, J. M.; Wania, F.; Arnot, J. A. Application of Mass Balance Models and the Chemical Activity Concept To Facilitate the Use of in Vitro Toxicity Data for Risk Assessment. Environ. Sci. Technol. 2014, 48 (16), 9770-9779.

(22) Gülden, M.; Seibert, H. In Vitro-in Vivo Extrapolation: Estimation of Human Serum Concentrations of Chemicals Equivalent to Cytotoxic Concentrations in Vitro. Toxicology 2003, 189 (3), 211-222.

(23) Heringa, M. B.; Hermens, J. L. M. Measurement of Free Concentrations Using Negligible Depletion-Solid Phase Microextraction (Nd-SPME). TrAC Trends Anal. Chem. 2003, 22 (10), 575-587.

OECD. Guidance Document on Good In Vitro Method Practices (GIVIMP); OECD Publishing: Paris, 2018.

(25) Baumann, J.; Dach, K.; Barenys, M.; Giersiefer, S.; Goniwiecha, J.; Lein, P. J.; Fritsche, E. Application of the Neurosphere Assay for DNT Hazard Assessment: Challenges and Limitations. In Methods in Pharmacology and Toxicology; Humana Press, 2015.

(26) Moors, M.; Rockel, T. D.; Abel, J.; Cline, J. E.; Gassmann, K.; Schreiber, T.; Schuwald, J.; Weinmann, N.; Fritsche, E. Human Neurospheres as Three-Dimensional Cellular Systems for Developmental Neurotoxicity Testing. Environ. Health Perspect. 2009, 117 
(7), 1131-1138.

(27) Ter Laak, T. L.; Mayer, P.; Busser, F. J. M.; Klamer, H. J. C.; Hermens, J. L. M. Sediment Dilution Method to Determine Sorption Coefficients of Hydrophobic Organic Chemicals. Environmenal Sci. Technol. 2005, 39 (11), 4220-4225.

(28) Birch, H.; Gouliarmou, V.; Lützhoft, H. C. H.; Mikkelsen, P. S.; Mayer, P. Passive Dosing to Determine the Speciation of Hydrophobic Organic Chemicals in Aqueous Samples. Anal. Chem. 2010, 82 (3), 1142-1146.

(29) Gouliarmou, V.; Smith, K. E. C.; De Jonge, L. W.; Mayer, P. Measuring Binding and Speciation of Hydrophobic Organic Chemicals at Controlled Freely Dissolved Concentrations and without Phase Separation. Anal. Chem. 2012, 84, 1601-1608.

(30) Birch, H.; Andersen, H. R.; Comber, M.; Mayer, P. Biodegradation Testing of Chemicals with High Henry's Constants - Separating Mass and Effective Concentration Reveals Higher Rate Constants. Chemosphere 2017, 174, 716-721.

(31) Birch, H.; Hammershøj, R.; Mayer, P. Determining Biodegradation Kinetics of Hydrocarbons at Low Concentrations: Covering 5 and 9 Orders of Magnitude of Kow and Kaw. Environ. Sci. Technol. 2018, 52 (4), 2143-2151.

(32) National Food Institute DTU. Danish (Q)SAR Database. National Food Institute, Technical University of Denmark. http://qsardb.food.dtu.dk/database/index.html (accessed Dec 17, 2018).

(33) Endo, S.; Escher, B. I.; Goss, K.-U. Capacities of Membrane Lipids to Accumulate Neutral Organic Chemicals. Environ. Sci. Technol. 2011, 45 (14), 5912-5921.

(34) Endo, S.; Goss, K.-U. Serum Albumin Binding of Structurally Diverse Neutral Organic Compounds: Data and Models. Chem. Res. Toxicol. 2011, 24 (12), 2293-2301.

(35) Jonker, M. T. O.; Van Der Heijden, S. A.; Kotte, M.; Smedes, F. Quantifying the Effects of Temperature and Salinity on Partitioning of Hydrophobic Organic Chemicals to Silicone Rubber Passive Samplers. Environ. Sci. Technol. 2015, 49 (11), 6791-6799. 
(36) Riedl, J.; Altenburger, R. Physicochemical Substance Properties as Indicators for Unreliable Exposure in Microplate-Based Bioassays. Chemosphere 2007, 67 (11), 22102220.

(37) Gilbert, D. Chapter 6: Molecular Carriers for Substrate Delivery: A Cross-Validation Study on in Vitro Biotransformation of PAHs Using Fish Liver S9 Enzyme Fractions. In PhD thesis: Using a reference partitioning phase to link exposure and effect assessment of hydrophobic organic chemicals - Novel equilibrium partitioning concepts and methods; Technical University of Denmark, 2015; p 151.

(38) Schirmer, K.; Chan, A. G. J.; Greenberg, B. M.; Dixon, D. G.; Bols, N. C. Methodology for Demonstrating and Measuring the Photocytotoxicity of Fluoranthene to Fish Cells in Culture. Toxicol. Vitr. 1997, 11 (1-2), 107-119.

(39) Tanneberger, K.; Rico-Rico, A.; Kramer, N. I.; Busser, F. J. M.; Hermens, J. L. M.; Schirmer, K. Effects of Solvents and Dosing Procedure on Chemical Toxicity in CellBased in Vitro Assays. Environ. Sci. Technol. 2010, 44 (12), 4775-4781.

(40) U.S. Environmental Protection Agency. ToxCast and Tox21SL chemical lists https://comptox.epa.gov/dashboard/chemical_lists (accessed Feb 26, 2019).

(41) Mayer, P.; Nyholm, N.; Verbruggen, E. M. J.; Hermens, J. L. M.; Tolls, J. Algal Growth Inhibition Test in Filled, Closed Bottles for Volatile and Sorptive Materials. Environ. Toxicol. Chem. 2000, 19 (10), 2551-2556.

(42) OECD. Guidance Document on Aqueous Phase Aquatic Toxicity Testing of Difficult to Test Chemicals; OECD Environmental Health and Safety Publications Series on Testing and Assessment; 23; Paris, 2018.

(43) Hartung, T.; De Vries, R.; Hoffmann, S.; Hogberg, H. T.; Smirnova, L.; Tsaioun, K.; Whaley, P.; Leist, M. Toward Good In Vitro Reporting Standards. ALTEX 2019, 36 (1), 3-17. 